Portland State University

PDXScholar

7-17-1974

\title{
Lingual discrimination of two normal-speaking populations
}

Janice Ellen Gould Nesbitt

Portland State University

Follow this and additional works at: https://pdxscholar.library.pdx.edu/open_access_etds

Part of the Speech Pathology and Audiology Commons Let us know how access to this document benefits you.

\section{Recommended Citation}

Nesbitt, Janice Ellen Gould, "Lingual discrimination of two normal-speaking populations" (1974). Dissertations and Theses. Paper 1995.

https://doi.org/10.15760/etd.1994

This Thesis is brought to you for free and open access. It has been accepted for inclusion in Dissertations and Theses by an authorized administrator of PDXScholar. Please contact us if we can make this document more accessible: pdxscholar@pdx.edu. 
AN ABSTRACT OF THE THESIS OF Janice Ellen Gould Nesbitt for the Master of Science in Speech: Emphasis in Speech Pathology/Audiology presented JuIy 17, 1974.

Title: Iingual Discrimination of Two Normal-Speaking Populations.

APPROVED BY MEMBERS OF THE THESIS COMMITTEE:

Robert H. English, Chaibran

$$
\text { Mary Gordon }
$$

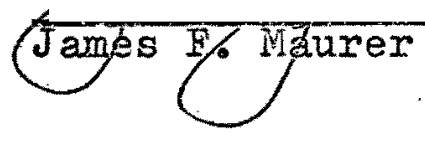

The present investigation was undertaken to collect normatfve data on a teenage population and a young adult population in order to assess tongue sensitivity regarding the identification of various geonetric shapes. The research was conducted to answer the following questions:

1. Is there a significant difference betiveen a teenage group and a young adult group regarding lingual discrimination?

2. What is the range and variability between and within the two groups?

3. Is the teenage group significantly better than 
the elementary school age group previously tested by Weiss (1973b)?

There were 50 normal-speaking subjects in the teenage grcup ranging in age from 13 through 15 years, and 50 normal-speaking young adults ranging in age from 22 through 26 years. The subjects in the teenage group were volunteers from the public schools of Portland, Oregon, and Camas, Washington. The adults were from the same areas and were either employed in responsible jobs or were enrolled in graduate study programs. All subjects were administered a passive and an active test of lingual discrimination. Each test included 24 identifications of plexiglass geometric shapes. Selection of the shapes were made by the subject pointing to his choice on a response sheet, after the geometric shape had been removed from his mouth. The results were analyzed statistically to assess mean, range, and variability within and between the groups. A t-test was used to determine a significance of differences.

The questions posed by this investigator were answered in the following manner:

1. There was no significant difference in performance between a teenage group and a young adult group regarding lingual discrimination. Thls would appear to contraindicate the belief by some authorities (McDonald and Aungst, 1967) that lingual discrimination abilities continue to improve until the midteens.

2. In discussing the results between the groups, the means of the active scores for both age groups were significantly greater than those achieved on the passive test. The variability on the passive test was significantly greater 
$(p>.05)$ for the teenage group than for the adult group. The adults tended to be more variable on the active test. This would tend to indicaie that both age groups were receiving more discriminative cues on the active test than on the passive test.

3. In comparing the teenage group to a group of 8year-olds previously tested by Weiss (1973b), it was found that the older group performed significantiy better. These findings held true for both passive and active tests. This finding is not surprising in that one would expect maturation in this discrimination task over time as a result of human development. 


\section{IINGUAI DISCRIMINATION OF TWO \\ NORMAL-SPEAKING POPULATIONS}

by

JANICE EITEN GOUID NESBITT

A thesis submitted in partial fulfillment of the requirements for the degree of

\section{MASTER OF SCIENCE} in

SPEECH: EMPHASIS IN SPEECH PATHOLOGY/AUDIOLOGY

Portland State University

1974 
TO THE OFFICE OF GRADUATE STUDIES AND RESEARCH:

The members of the Committee approve the thesis of Janice Ellen Gould Nesbitt presented July 17, 1974.

Robert H. English, Chajirman

Mary Gordon

James Finrés

APPROVED:

Robert W. Vogelgang, Heag; Department of Speech

David T. Clark, Dean of Graduate Studies and Research

July: 22, 1974 


\section{ACKNOWLIEDGNENTS}

I wish to express my sincere appreciation to the chairman of my thesis committee, Dr. Robert H. English, for his support, guidance, and perseverance which made completion of this project possible.

My gratitude is also expressed to Dr. Curtis Weiss from whom the idea for this investigation originated, and whose cooperation has been most helpful.

Thanks are extended to Dr. Ronald Smith, a member of my committee, and Dx. Chadwick Karr, both psychologists at Portland State University, for sharing their expertise and technical assistance in the statistical analysis of the data. A very special thanks goes to Judith Widen, audiologist at the Portland Center for Hearing and Speech, for unlimited hours spent in statistically computing and onalyzing the data.

I wish to acknowledge and thank the other members of my committee, Mary Gordon, who read every draft and whose suggestions have been invaluable, and Dr. James Maurer, who has been most cooperative in helping me finish this task.

Finally, I offer heartfelt thanks and appreciation to my family, particularly my son; Rob, and daughter, Nancy, and all my friends for their unceasing encouragement, help, and patience during this extended project. 
TABLE OF CONTENTS

PAGE

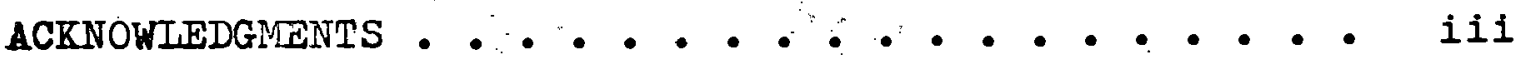

IIST OF TABIES. •.................. • vi

LIST OF FIGURES . . . . . . . . . . . • • . Vii

CHAPTER

I INTRODUCTION AND STATEMENT OF THE PROBLEM • 1

Introduction. .......... 1

Statement of the Problem. . . . . . 3

Specific Questions to be Answered . . . 3

Definition of Terms . . . . . . . 3

II REVIEW OF THE LITERATURE. • . . . • • . 6

III METHODS AND PROCEDURES. . . . . . . 12

Subjects. . . . . . . . . . 12

Equipment ........... . 13

Administration of Tests . . . . . 14

Test Environment

Method

IV RESULTS AND DISCUSSION OF RESULTS . . . . 18

Results . . . . . . . . . 18

Discussion of Results . . . . . . 25

$\nabla$ SUMMARY AND IMPLICATIONS. . . . . . . 29

Summary . . . . . . . . . 29 
CHAPTER

PAGE

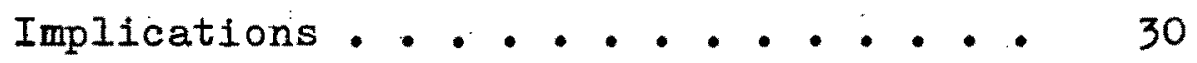

Conclusion:.......... 32

BIBIIOGRAPHY . . . . . . . . . . . . . . 34

APPENDICES. . . . . . . . . . . . . . . . . . 39

A: The Set of 24 Geometric Shapes Used for

Assessing Iingual Discrimination. . . . . 40

B: Illustration of 24 Shapes Used for

Assessing Lingual Discrimination. . . . . 41

C: A Typical Response Sheet. - . . . . . 43

D: An Example of the Score Sheet Used for

AlI Subjects. . . . . . . . . . . 44

E: Instruction to Subjects... . . . . . 45 


\section{IIST OF TABLES}

TABIE

PAGE

I Means, Standard Deviations (SD), and t-Test

Scores for Combined Teenage and Young

Adult Groups . . . . . . . . . . .

II Means, Standard Deviations (SD), and $t-T e s t$

Scores Comparing Passive and Active

Administrations of the Test for Each

Group.................... ...

III Comparison of Means, Standard Deviations

(SD), and t-Test Scores Between Males

and Females of a Teenage Group and a

Young Adult Group. . . . . . . . . .

IV Comparison of Means, Standard Deviations

(SD), and t-Test Scores Between a

Teenage Group and an 8-Year-01d Group. . 
IIST OF FIGURES

FIGURE

PAGE

1 Comparison of Mean Total Scores and Standard

Deviations (SD) for Each Group in Passive and Active Discrimination Tasks . . . . 
CHAPTER I

INTRODUCTION AND STATEMENT OF THE PROBLEM

\section{INTRODUCTION}

The process of speech is an important and complex system, not only to every individual, but to society as a whole. Articulation is no small part of this total speech system. The American Speech and Hearing Association Committee on the Midcentury White House Conference (1952) rerealed that in a population of speech handicapped children, ages 5 to 21 years, 60 percent had functional articulation problems. Another 16 percent of these children were found to have misarticulations which could be related to organic conditions such as cleft palate, cerebral palsy, malocclusions, and/or hearing impairment (Irwin, 1969; Van Riper, 1963).

Because of the overwhelming percentage of articulation problems among the communicatively handicapped, considerable research has been conducted to evaluate both functional and organic etiologies. These studies were concerned primarily with the motor end-organs, such as the articulators. In recent years consideration has been given to the possibility that the motor performance of speech could be influenced by variations in sensory perception 
within the oral cavity. According to McCall (1969), the relationship between these two parameters may be explained as follows:

Based on current knowledge of oral physiology, we can postulate at least four tactile sensory skills that appear to have a priori relevance to the acts of speaking, chewing, and swallowing: (1) detection of the presence of tactile stimuli and appreciation of minimal changes in tactile stimulation; (2) spatial discrimination and localization of tactile stimuli; (3) temporal discrimination of tactile stimuli; and (4) appreciation of simultaneous bilateral tactile stimuli.

Within the oral structure the tongue is of primary importance in the articulation of sounds and efficiency of speech production. As a child matures, his tongue also matures and articulation, therefore, becomes more precise and refined as lingual discriminative abilities improve. For example, a 3-year-old child would not be expected to have mastered the intricate tongue movements necessary for producing such words as "swing, slide, or stork," but an 8-year-old child would be expected to be proficient in producing all phonemes. A 14-year-old would have a faster rate and be even more precise and efficient in his speech production.

This writer has been interested in the probable age at which maturation of the tongue is complete. Introducing stimuli intraorally which require lingual discrimination through sensory avenues is one method of assessing this parameter. 


\section{STATEMENT OF THE PROBLEM}

A review of the literature revealed a paucity of research dealing with the age at which maturation of the motor and sensory development of the tongue is complete. There is a need to study normal-speaking age groups to assess their oral sensory perception ability through lingual discrimination. Hence, the present investigation. was designed to collect normative data on teenage and young adult populations in order to study tongue sensitivity in identifying various geometric shapes.

\section{SPECIFIC QUESTIONS TO BE ANSWERED}

The specific questions this investigation has sought to answer include:

1. Is there a significant difference between a teenage group and a young adult group regarding lingual discrimination?

2. What is the range and variability between and within the two groups?

3. Is the teenage group significantly better than the elementary school age group previously tested by Weiss (1973)?

\section{DEFINITION OF TERMS}

It is necessary to establish definitions for specific operational terms which have been utilized in this study.

A term called oral stereognosis has been defined by Woodford (1967): 
- . the faculty of perceiving the three-dimensional qualities (shapes) of objects examined oraliy and of identifying them, while ariy inability to perform this task represents astereognosis regardless of where the defect lies or whether it is organic or functional.

This study was designed primarily to evaluate sensations perceived by the tongue and so the term "tongue sensitivity" has been substituted for oral stereognosis. Hence, the operational terms employed in this paper are defined as follows:

\section{Tongue Sensitivity}

The faculty of perceiving the quaiities of threedimensional shapes by examining them orally, both passively and actively, with the tongue (Weiss, 1973).

Passive Discrimination

Identifying a geometric shape that has been placed on the anterior portion of the tongue while the tongue is lying at rest on the floor of the mouth directly behind the lower central incisors. The mouth is in a relaxed, open position (Weiss, 1973).

Active Discrimination

Identifying a geometric shape by exploring all its dimensions with the tongue while the object is held directly behind the upper central incisors and the mouth is in a relaxed, open position. In this discriminative task, the tongue is free to move actively over the shape (Heiss, 1973). 
Teenage Population

For the purposes of the present investigation, the teenage population has consisted of normal-speaking white individuals ranging in age from 13 through 15 years.

Young Adult Population

The young adult population included normal-speaking white individuals 22 through 26 years of age. 
CHAPTER II

REVIEW OF THE IITERATURE

Interest in oral sensory perception has increased markedly during recent years and has resulted in the instigation of numerous investigations. A relatively current starting point for this impetus in research was two speech models designed by Falrbanks (1954) and Mysak (1959). These models described speech as a servosystem in which considerable emphasis was placed on sensory feedback and its relation to the efficient movements for speech. The oral-sensory organism which operates on this servosystem principle tends to depend on those sensory channels which are most efficient and make the greatest contribution to the control of output. Many investigations have examined several different sensory parameters.

Some of these investigators have sought to explore the hypothesis that the tongue is the most sensitive part of the body. To do this, tests were devised to assess twopoint discrimination which refers to the recognition of the separateness of two simultaneous stimuli. Ringel. (In Bosma, 1970) designed an esthesiometer which controlled the distance and applied pressure between two stimulus points on the skin's surface. His results, like those of other re- 
searchers such as Henkin and Ranks (In Bosma, 1967) who tested with nylon filaments, or Rutherford and McCall (In Bosma, 1967) who used calipers, found that the tongue tip was not only the most sensitive oral area, but the least susceptible to variability. The lips were somewhat less sensitive, and the palate was found to be significantly more sensitive than the blade of the tongue. Other investigators confirmed these findings (Grossman, 1964; Ringel and Ewanowski, 1965; McCall, 1969; Pleasonton, 1970). A recent researcher (Fucci, 1973) who used electric vibration to test oral sensation thresholds; added further support to the preceding results.

Best and Taylor (1963) developed an interesting table in which several different body regions were compared with regard to the minimal distance by which two simultaneous stimuli had to be separated in order to arouse a double sensation. The following were four examples from their study:

$\begin{array}{lr}\text { Tip of tongue } & 1.1 \mathrm{~mm} \\ \text { Red part of lips } & 4.4 \mathrm{~mm} \\ \text { Palm of hand } & 11.3 \mathrm{~mm} \\ \begin{array}{l}\text { Middle of back of } \\ \text { upper arm }\end{array} & 67.0 \mathrm{~mm}\end{array}$

Another area of research has been designed to inhibit sensory transmission pathways in order to ascertain if there is an effect on speech efficiency. This already had been accomplished auditorily through delayed auditory feedback 
(DAF), but the investigators sought to determine the effects of anesthetizing the oral sensory mechanism. McCroskey (1958) found that by anesthetizing the articulators and eliminating the tactile feedback that a decrease in intelligibility and word accuracy resulted. In similar studies, Ringel and Steer (1963) agreed that articulation performance decreased.

Weiss (1969) suggested, however, that the misarticulations observed may have been more the result of disrupted motor functions, rather than disrupted tactile feedback, since topical anesthesia did not affect articulation. In other studies, Weiss (1969; 1970) found that Iinguapalatal taction provided little afferent information in articulation proficiency. This supported research by Schliesser and Coleman (1968) where it was found acceptable speech could be produced, in spite of anesthetization. These investigations refute the findings of McCroskey (1958) and Ringel and Steer (1963).

A third area of research which has been undertaken to determine the role of oral sensory acuity in articulation has been called "oral stereognosis." Ruch and Patton (1965) have defined stereognosis as the awareness of the form of objects by palpation without the aid of vision. This definition has been modified to include the exploration of objects orally (Arndt, 1970).

A variety of instruments and procedures have been 
developed to assess oral form discrimination. These, for the most part, have included geometric shapes of various sizes and shapes which are presented intraorally. Two of the initial, fairly standard tests of oral stereognosis were designed by Class (In Bosma, 1967) and Shelton, et al. (1967). Both the Class and Shelton tests utilized 20 stemmounted geometric forms developed by the National Institute of Health (NIH) and the National Institute of Dental Research (NIDR) respectively. Torrans (1973) provided a review of methodologies used in thirty-two studies of oral stereognostic abilities.

Later studies used similar forms but evaluated variables such as the size of the shapes (Dellow, et al., 1970); attachments on the forms (IaPointe and Williams, 1971); education, sex, and fatigue of the subjects (Williams and IaPointe, 1971); and age of the subjects (McDonald and Aungst, 1967).

Class (In Bosma, 1967) tested four groups in her study: stutterers, individuals with articulation errors, cerebral palsied individuals with speech deviations, and normal speakers. She found significant differences between the groups, both in number of correct responses and length of time for identification. The normal speakers required a shorter time period and made the most correct responses. Similar findings by other researchers have concurred that speech defective individuals achieved lower oral 
stereognostic scores (Fucci and Robertson, 1971; Moser and Houch, In Bosma, 1970).

Other investigato=s, however, have found no positive correlations between normal speech production and the ability to identify geometric shapes (Weiss, 1973a; Weinberg, et al., In Bosma, 1970; McDonald and Aungst, In Bosma, 1967).

Weiss (1973b) conducted an investigation using a set of 24 geometric shapes which he had designed. The subjects were normal-speaking, 8-year-old children. He compared active with passive lingual discrimination and found the children performed significantly better on the active identification. Weiss (1973b) also assessed tongue laterality between the males and females and found no significant difference.

Skalbeck and Weiss (1974) investigated tongue sensitivity among deaf children. Their subjects were 8- and 9year-old, oral-speaking individuals. The results indicated the deaf children to be sigrificantly better than normalspeaking children on the test of passive discrimination. There was no significant difference on the active administration.

The foregoing review of the literature has provided a background for the present investigation. In addition, it is to be observed that, in spite of the diversity of the research, little attempt has been made to develop normative 
data relative to lingual. discrimination. The first normative study relative to lingual discrimination this investigator is aware of was conducted by Weiss (1973b). Hence, working under the guidance of Weiss, this investigator designed the present investigation in an effort to extend his normative data from the teenage years up through the joung adult years. 


\section{CHAPTER III}

\section{METHODS AND PROCEDURES}

\section{SUBJECTS}

Fufty normal-speaking, teenage subjects were selected, ranging in age from 13 through 15 years. There was an even sex distribution with 25 boys and 25 girls. These students were volunteers from classes and study halls in the public schools of Portland, Oregon, and Camas, Washington.

A normal-speaking, young adult population which consisted of 25 males and 25 females, ranging in age from 22 through 26 years, was also selected. The subjects were from Portland, Oregon, and Camas, Washington areas and were either employed in responsible jobs or were enrolled in graduate study programs.

For inclusion in this study, each subject met the following criteria:

1. No diagnosed or recognizable neuromuscular disorder;

2. no history of treatment for a speech disorder;

3. no developmental deviations in speech as assessed by informal conversation and inspection;

4. no observable deviations from normal dentition or hearing as assessed informally by the investigator;

5. no observable deviation from normal mental 
ability as evidenced by the maintenance of a responsible job and/or average or better school record; and

6. no previous information or familiarity with the nature and purpose of the study or context of the test.

After the subjects were selected, they were requested not to eat, drink, chew, or smoke for a minimum of fifteen minutes prior to the test administration.

\section{EQUIPMENY}

For the purposes of this study a set of 24 different geometric shapes was used. These shapes had been designed by Weiss and were consistent with his studies (1969; 1970; 1973a; 1973b). The shapes were made from one-fourth-inch plexiglass. Each shape was one-half inch at its greatest dimension, either length or width, and was attached to a five and one-fourth-inch curved handle made from .004 orthodontic wire (see Appendix A).

It was necessary to familiarize the subjects with the various shapes which they would be encountering in the discriminative tasks. This was done by depicting all 24 shapes on two, eight and a half-inch by eleven-inch sheets. (Refer to Appendix B.)

A set of 24, eight and a half-inch by five and a halfinch pages were used by the subjects to indicate their choices. Each page had illustrations of six of the geometric shapes, one of which was the correct response, and 
at least one other which was similar in shape to the correct response. For example, two similar triangles might appear on one response sheet, while on another there would be a circle, a circle with a hole in its center, and a circle with a notch cut out at the top. This is illustrated in Appendix $C$.

Score sheets were designed to include the subject's name, sex, age, grade and/or occupation, date, time of testing, right and wrong responses for both passive and active discrimination tasks, and total number of right and wrong responses. A sample of the score sheet is to be found in Appendix D. A screen measuring fourteen inches high and sixteen inches long was used to shield the shapes and the score sheet from the subject's vision. All geometric shapes were rinsed in hot water and sterilized in a zepherin chloride solution.

\section{ADMINISTRATION OF TESTS}

\section{Test Environment}

The testing took place in a quiet room in either the home of the investigator or the subject, or at the Portland Center for Hearing and Speech. This was necessary to insure a supply of hot water. The subject was alone with the investigator throughout the testing procedure.

\section{Method}

A maltiple-choice test of lingral discrimination was 
adminisiered consisting of 24 different geometric shapes. To insure consistency between studies by Weiss and the present investigation, this investigator had been trained and observed by Weiss in the use of the instruments.

The investigator sat across a table from the subject, but within arm's length of him, with the screen separating them. The shapes were arranged in order of presentation behind the screen and out of the subject's sight. Before beginning actual testing, each subject was given the opportunity to look at the two sheets depicting all geometric shapes, with the investigator stating, "I want you to look at all these shapes." One of the shapes, a plexiglass triangle, was introduced with the instructions, "Point to the picture which looks like this." These sheets and the shape were then removed and verbal instructions given to the subject preceding both the active and passive administrations of the test. These instructions are provided in Appendix E.

The order of the two discriminative tasks was randomlzed so that the passive test was given first one half of the time, and one half of the time the active test was presented first. This was done in order to curtail learning which might occur due to famillarity with the shapes, and, hence, effect the Iinal results of this investigation. Each shape was introduced individually into the subject's mouth at the same angle pictured on the response pages from which 
he would make his selection. The investigator held the handle in order to stabilize the angle and to maintain an essentially equal degree of pressure. After a five-second duration (determined with a stopwatch), during which time the subject had his eyes shut and his mouth open, the shape was removed and placed behind the screen. The subject was then instructed to open his eyes and point to one of the six pictures that he thought represented the stimulus shape. The responses were scored right or wrong, but when the response was wrong, the specific shape chosen was noted on the score sheet. The response sheet was not brought into view until after the shape had been removed from the subject's mouth.

The complete set of 24 shapes was presented for both the passive and active tests, making a total of 48 identifications. During the passive test administration the subject held his tongue stationary just behind his lower central incisors and the shape was placed lightly on the tongue about one-eighth inch behind the tongue tip for five seconds. The subject was requestied to keep his mouth open and to more no part of the oral structure. During the active test administration the shapes were held directly behind the upper central incisors for five seconds. The handle, held by the investigator, was firmly secured in the interdental space between the two teeth. The subject was asked to explore the shapes actively with his tongue while keeping his 
mouth open.

When the testing was completed, which took about 30 minutes, the scores were totaled and any questions the subject had regarding the test and/or his performance were answered. After each subject was tested, the forms were rinsed in hot water and sterilized in zepherin chloride. 


\section{CHAPTER IV}

\section{RESUITS AND DISCUSSION OF RESUITS}

\section{RESULTS}

There has been a need to study normal-speaking age groups to assess maturation of their oral sensory perception ability through lingual discrimination. This study has been designed to collect normative data on teenage and young aduIt populations in order to study tongue sensitivity in the identiflcation of various geometric shapes. The research was conducted to answer the following questions:

1. Is there a significant difference between a teenage group and a young adult group regarding lingual discrimination?

2. What is the range and variability between and within the two groups?

3. Is the teenage group significantly better than the elementary school age group previously tested by Weiss $(1973 \mathrm{~b})$ ?

Statistical analyses of the data included mean, range, and variability. scores for males and females in both age groups on passive and active tests of lingual discrimination. In addition, comparison of lingual discrimination was. made within the teenage group and young adult group, as well as comparisons between each group.

Table I compares the teenage population with the young 
adult population. For the passive administration, the ranges for both groups were similar. Out of a possible 24 correct selections, the teenage group achieved scores ranging from 6 to 16 , and the adult group's scores ranged from 7 to 14. Mean scores were nearly identical: the teenage group was 11.14 and the adult group 10.94. Statistical analysis of these two means using the t-test showed no significant difference between the teenage and adult populations.

As with the passive tests, the teenage group and the adult group scored similarly on the active administration. Scores ranged from 6 to 19, with a mean of 14.62 for the

\section{TABLE I}

MEANS, STANDARD DEVIATIONS (SD), AND t-TEST SCORES FOR COMBINED TEENAGE AND YOUNG ADUIT GROUPS

\begin{tabular}{lcccc}
\hline \hline Group & Test & $\overline{\mathrm{x}}$ & SD & $\begin{array}{c}\text { t-Test } \\
\text { Score* }\end{array}$ \\
\hline Teenage & Passive & 11.14 & 2.43 & .825 \\
Adult & Passive & 10.94 & 1.75 & \\
& & & & \\
Teenage & Active & 14.62 & 1.89 & 1.38 \\
Adult & Active & 15.16 & 2.01 & \\
\hline
\end{tabular}

*Significant at .05 level.

Computed with 98 degrees of freedom. 
teenage population. The scores of the adult population ranged from 12 to 19, averaging 15.16. Again, a t-test analysis showed differences between the two age groups to be non-significant.

The standard deviation for the teenage group on the passive test (2.43) was greater than the standard deviation for the adult group (1.75). A two-variance F-test was used to analyze any significant differences in variability. The variability on the passive test was significantly greater $(p>.05)$ for the teenage group than for the adult group. In contrast, the variance of the older group on the active test was greater than that of the teenage group, but the difference was not significant.

Careful examination of Table II shows both the males and females performed better on the active test than on the passive test. Scores for teenage boys averaged 10.84 for the passive test, as compared to 14.68 on the active test. Teenage girls achieved a passive mean of 11.44 and an active mean of 14.56. The mean scores for the adult females on the passive test were 11.24, while their active test mean was 15.08. Finally, the adult males had a passive test mean of 10.64, and an active test mean of 15.24. For all groups the differences between active and passive administrations were significant at the .001 level of confidence. Use of the two-variance F-test revealed that the teenage group demonstrated significantiy more variability on the passive test 
TABLE II

MEANS, STANDARD DEVIATIONS ( $S D$ ), AND $t$-TEST SCORES CONPARING PASSIVE AND ACTIVE ADMINISTRATIONS OF THE TEST FOR EACH GROUP BY SEX

\begin{tabular}{|c|c|c|c|c|}
\hline Group & Test & $\overline{\mathbf{x}}$ & $S D$ & $\begin{array}{l}\text { t-Test } \\
\text { score* }\end{array}$ \\
\hline $\begin{array}{c}\text { Teenage Boys } \\
n\end{array}$ & $\begin{array}{l}\text { Passive } \\
\text { Active }\end{array}$ & $\begin{array}{l}10.84 \\
14.68\end{array}$ & $\begin{array}{l}2.27 \\
1.77\end{array}$ & 10.98 \\
\hline $\begin{array}{c}\text { Teenage Girls } \\
\text { " }\end{array}$ & $\begin{array}{l}\text { Passive } \\
\text { Active }\end{array}$ & $\begin{array}{l}11.44 \\
14.56\end{array}$ & $\begin{array}{l}2.60 \\
2.04\end{array}$ & 6.96 \\
\hline $\begin{array}{c}\text { Adult Females } \\
n\end{array}$ & $\begin{array}{l}\text { Passive } \\
\text { Active }\end{array}$ & $\begin{array}{l}11.24 \\
15.08\end{array}$ & $\begin{array}{l}1.66 \\
2.08\end{array}$ & 9.44 \\
\hline $\begin{array}{c}\text { Adult Males } \\
n \quad n\end{array}$ & $\begin{array}{l}\text { Passive } \\
\text { Active }\end{array}$ & $\begin{array}{l}10.64 \\
15.24\end{array}$ & $\begin{array}{l}1.82 \\
1.98\end{array}$ & 10.78 \\
\hline
\end{tabular}

*Significant at .001 level.

Computed with 24 degrees of freedcm.

than on the active test. The adult group, however, showed no difference in variability when comparing active and passive administrations.

Further examination revealed no significant differences between males and females of either age group. These 
äfferences are tabulated in Table III.

The data in the preceding three tables are summarized in Figure 1. As the figure graphically shows, there was no significant difference between the two age groups on tests of lingual discrimination.

\section{TABLE III}

COMPARISON OF MEANS, STANDARD DEVIATIONS, AND $t$-TEST SCORES BETWEEN MATES AND FEMALES

OF A TEENAGE GROUP AND A YOUNG

ADUIT GROUP

\begin{tabular}{llccc}
\hline \hline Group & Test & $\bar{x}$ & SD & $\begin{array}{c}\text { t-Test } \\
\text { Score* }\end{array}$ \\
\hline Teenage Boys & Passive & 10.84 & 2.27 & .221 \\
Teenage Girls & Passive & 11.44 & 2.60 & \\
Teenage Boys & Active & 14.68 & 1.77 & .870 \\
Teenage Girls & Active & 14.56 & 2.04 & .832 \\
Adult Males & Passive & 10.64 & 1.82 & \\
Adult Females & Passive & 11.24 & 1.66 & .878 \\
& & & & \\
Adult Males & Active & 15.24 & 1.98 & \\
Adult Females & Active & 15.08 & 2.08 & \\
\hline
\end{tabular}

*Significant at .05 level.

Computed with 48 degrees of freedom. 


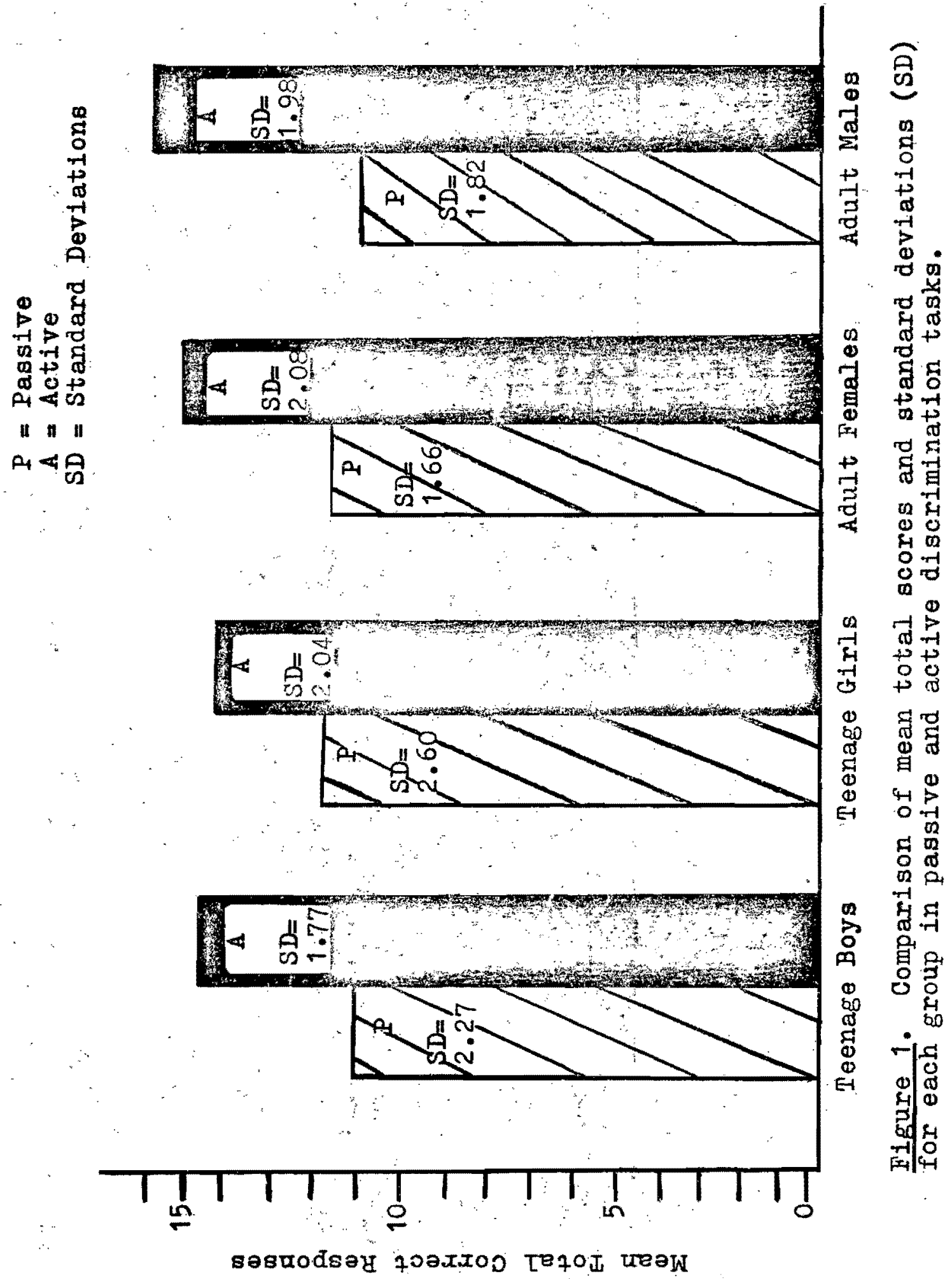


The results of an investigation conducted by Weiss (1973b) were obtained in order to compare an elementary school age group with the teenage group tested in the present investigation. Weiss tested a group of normalspeaking 8-year-olds for passive and active lingual discrimination, utilizing the same equipment and similar procedures as the current study. The subjects were closely matched in sex, socioeconomic status, and intelligence. As can be seen in Table IV, the teenage group performed significantly better than the 8-year-old group on both the passive administration $(6.08)$ and the active administration (3.34).

$$
\begin{gathered}
\text { TABLE IV } \\
\text { COMPARISON OF MEANS, STANDARD DEVI ATIONS (SD), } \\
\text { AND t-TEST SCORES BETWEEN A TEENAGE } \\
\text { GROUP AIND AN 8-YEAR-OLD GROUP* }
\end{gathered}
$$

\begin{tabular}{lcccc}
\hline \hline Group & Test & $\overline{\mathrm{x}}$ & SD & $\begin{array}{c}\text { t-Test } \\
\text { Score** }\end{array}$ \\
\hline 8-Year-0ld & Passive & 8.04 & 2.4 & 6.08 \\
Teenage & Passive & 11.14 & 2.43 & \\
8-Year-0ld & Active & 12.68 & 3.6 & 3.34 \\
Teenage & Active & 14.62 & 1.89 & \\
\hline
\end{tabular}
$(1973 b)^{*}$.

*Eight-year-old group previously tested by Weiss

**Significant at .01 level.

Computed with 88 degrees of freedom. 


\section{DISCUSSION OF RESULTS}

The first question the present investigation sought to answer was: Is there a significant difference between a teenage group and a young adult group regarding lingual discrimination? The answer to this question is clearly indicated in Tables I through III and in Figure 1. We can see that no significant difference was found between the two age groups. This would indicate that no significant maturation of the oral sensory system appears to take place after the age of 13 years.

This finding is in conflict with a study conducted by McDonald and Aungst (1967) in which they reported that the ability to discriminate shapes in the oral cavity continued to improve until the midteens. The results of the present investigation would tend to modify the McDonald and Aungst hypothesis in that lingual discriminative ability might advance until early teens, but not thereafter.

The second question investigated in this study was: What is the range and variability between and within the two groups? After finding no significant difference in overall performance between the two age groups, the data were analyzed to see if differences existed between the passive and active tests for both sexes of each group. Table II and Figure 1 indicate that in every situation the means of the active scores were significantly greater than 
those achieved on the passive test for both sexes. Due to the nature of the two tasks, these results could have been expected. In the passive test, the individual was instructed not to move his tongue and, hence, the stimulation was dependent only on tactile cues. During the active administration, however, the individual was free to pursue the dimensions of the several shapes with his tongue, and, thus, tactile and proprioceptive cues were received. Weiss (1973a) states, "Proprioception is the tongue's ability to feel sensations the tongue itself generates."

The variability on the passive test was significantly greater $(p>.05)$ for the teenage group than for the adult group. In contrast, the variance among adults on the active test was greater than the teenage group, but the difference was not significant. The variability displayed by the teenage population on the passive test might be explained by the fact that some of the teenage individuals unconsciously explored the shapes to a slight degree, even though instructed not to do so. The variability among the adults on the active test is perhaps due to the fact that this investigator noted many subjects tended to attack the shapes more aggressively than other subjects, and perhaps attained a higher or lower score because of it.

In analyzing performances within the two groups on the passive and active tests, it was found that the teenage group demonstrated significantly more variability on the 
passive administration than on the active. There was no variability, however, between active administration and passive administration results for the young adult group. An analysis between the sexes also revealed no differences of significance in variability.

The fact that the results from the teenage group tended to be more variable on the passive test, both within their own group and as compared with the young adult group, might suggest that this test is not as definitive for the teenage group. In other words, it would seem if normalspeaking subjects exhibited significant variability on this test, we might see even a greater range in a teenage population with anatomical or physiological problems. These findings also might suggest that variability tends to decrease as a result of age and maturation.

The final question asked in this investigation was: Is the teenage group significantly better than an elementary school age group? Comparing the two groups in question, it can be seen by looking at Table IV that the teenage group performed significantly better than the normal-speaking 8year-old group tested by Weiss (1973b). These results occurred for both the passive and active tests.

From this information, we might possibly hypothesize that maturation of the oral sensory system is not complete at the age of 8 , but is final somewhere between the ages of 8 and 13. Support for this hypothesis comes from Ringel, 
et al. (1970) who conducted a study of 8-year-old children, half with normal articulation and half with varying degrees of articulation disorders. These were contrasted with normal-speaking adult subjects and speech defective adults. The study varied from this research in that only 10 geometric shapes were used and the subjects were required to decide whether shapes were the same or different. The results indicated that the adults with articulation errors performed better than did children with normal articulation. Since the present investigation has found no significant differences between a teenage group and an adult group, it is felt that the two groups may be considered as one, when comparing their performances to a group of joung children. Perhaps the older group is considerably better on the active discrimination due to a better-developed motor system which allows for more precise and appropriate lingual manipulation of the stimulus shapes. The increase in performance by the older groups on the passive test could be explained by the fact that the sensory modalities relating to tactile feedback are more acute as a function of age. There also could be a structural maturation, whereby the oral cavity and facial structures are incomplete in the young child, and, thus, inhibits adequate lingual manipulation of the test shapes. 
CHAPTER V

SUMMARY AND IMPLICATIONS

SUMMARY

The present investigation was undertaken to collect normative data on a teenage population and a young adult population in order to assess tongue sensitivity regarding the identification of various geometric shapes. The research was conducted to answer the following questions:

1. Is there a significant difference between a teenage group and a young adult group regarding. lingual discrimination?

2. What is the range and variability between and within the two groups?

3. Is the teenage group significantly better than the elementary school age group previously tested by Weiss (1973b)?

There were 50 normal-speaking subjects in the teenage group ranging in age from 13 through 15 years, and 50 normal-speaking young adults ranging in age from 22 through 26 years. The subjects in the teenage group were volunteers from the public schools of Portland, Oregon, and Camas, Washington. The adults were from the same areas and were either employed in responsible jobs or were enrolled in graduate study programs. AII subjects were administered"a passive and an active test of lingual discrimination. Each 
test included 24 identifications of plexiglass geometric shapes. Selection of the shapes were made by the subject pointing to his choice on a response sheet, after the geometric shape had been removed from his mouth. The results were analyzed statistically to assess mean, range, and variability within and between the groups. A t-test was used to determine a significance of differences.

The questions posed by this investigator were answered in the following manner:

1. There was no significant difference in performance between a teenage group and a young adult group regarding lingual discrimination. This would appear to contraindicate the belief by some authorities (McDonald and Aungst, 1967) that lingual discrimination abilities continue to improve until the midteens.

2. In discussing the results between the groups, the means of the active scores for both age groups were significantly greater than those achieved on the passive test. The variability on the passive test was significantly greater $(p>.05)$ for the teenage group than for the adult group. The adults tended to be more variable on the active test. This would tend to indicate that both age groups were receiving more discriminative cues on the active test than on the passive test.

3. In comparing the teenage group to a group of 8year-olds previously tested by Weiss (1973b), it was found that the older group performed significantly better. These findings held true for both passive and active tests. This finding is not surprising in that one would expect maturation in this discrimination task over time as a result of human development.

\section{IMPLICATIONS}

The present investigation lends itself ideally to 
research in several possible areas:

First, the data obtained in this study indicate that a teenage group, including 13 through 15 years, performed significantly better on both tests than did an 8-year-old group. A study similar to the current investigation needs to be conducted to determine at what age performance ceases to improve significantly in normal-speaking individuals.

Second, using similar techniques and shapes, normative studies should be conducted with groups older than those tested in this investigation in order to learn at what age there is a reduction of performance in the oral sensory mechanism.

Third, the possibility of developing a mini-test should be considered, using approximately ten of the shapes. The test would include shapes ranging from easily recognizable (circle) to very difficult to discriminate (two triangles). This mini-test should eventually become an integral part of the oral examination to assist in the assessment of articulation proficiency.

Fourth, a study should be conducted comparing two groups who fall within the range of normal speakers, but who are at opposite ends of the continuum in that one group speaks very slowly and the other group speaks extremely rapidily.

Fifth, our news media has been full of the physical harm that can result from smoking cigarettes, particularly 
to the lungs and heart. To this investigator's knowledge, no research has been undertaken by speech pathologists to determine the effect of smoking on lingual sensitivity. Could there possibly be any correlation between smoking and proficlency in speaking? In the same light, what effect does marijuana in a person's system have on his speech? Sixth, it would be interesting to conduct a similar study on a dysphasic population, not only to ascertain the possible degree their lingual discrimination abilities have been impaired, but also to aid in deciding the mode of speech and language treatment, both procedures and techniques. This investigator is not suggesting that such tests or techniques be applied indiscriminately to all dysphasic individuals.

\section{CONCLUSION}

In conclusion, this investigation has shown that there is no significance of difference between a teenage population and a young adult population on tasks of lingual discrimination. This would tend to modify findings by MoDonald and Aungst (In Bosma, 1967) in which they found that improvement of lingual discrimination continued into the mid-teens.

In addition it was found that both age groups performed significantly better on the active administration than on the passive administration. 
Finally, it was found that the teenage group performed significantly better than an 8-year-old group previously tested by Weiss (1973b).

Future investigations will extend the normative information available on lingual discrimination. 
$\underline{B} \underline{\underline{B}} \underline{\underline{I}} \underline{\mathrm{O}} \underline{\underline{G}} \underline{\mathrm{R}} \underline{\mathrm{A}} \underline{\underline{P}} \underline{\mathrm{Y}}$ 


\section{BIBIIOGRAPHY}

American Speech and Hearing Association Committee on the Midcentury White House Conference, "Speech Disorders and Speech Correction." J. Speech and Hearing Dis., 27, 130 (1952).

Arndt, William B., Gauer, Judith, Shelton, Ralph, Crary, D., and Chisum, Linda, "Refinement of a Test of Oral Stereognosis," in Bosma,-J.F., (ed.), Second Symposium on Oral Sensation and Perception. Springfield, Ill.: Charles C. Thomas (1970). pp. 363-378.

Best, C. H. and Taylor, N. B., The Human Body. N. Y.: Holt, Rinehart and Winston (1963). pp. 625-628.

Class, Iois W., "A Comparative Study of Normal Speakers and Speech Defectives with Regard to the TactuaIKinesthetic Perception of Forms with the Tongue," Unpublished master's thesis, Ohio State University (1956), in Bosma, J. F. (ed.), Symposium on Oral Sensation and Perceotion. Springfield, Ill.: Charles C. Thomas (1967). pp. 244-286.

Dellow, P. G., Iund, J. P., Babcock, K., and Rosendaal, G. Van, "The Oral Assessment of Object Size." J. Speech and Hearing Res., 13, 526-536 (1970).

Fairbanks, G., "A Theory of the Speech Mechanism as a Servosystem." J. Speech and Hearing Dis., 19, 133-139 (1954).

Fucci, Donald, "Oral Vibrotactile Sensation: An Evaluation of Normal and Defective Speakers." J. Speech and Hearing Res., 15, 179-184 (1973).

and Robertson, John H., "'Functional' Defective Articulation: An Oral Sensory Disturbance." Perceptual and Motor Skills, 33, 711-714 (1971).

Grossman, R. C., "Methods for Evaluating Oral Surface Sensation." J. Dental Res., 43, 301-309 (1964). 
Henkin, Robert and Ranks, Velma, "Tactile Perception on the Tongue, Palate and the Hand of Normal Man," in Bosma, J. F. (ed.), Symoosium on Oral sensation and Perception. Springfield, Ill.: Charles C. Thomas (1967). pp. 182-187.

Irwin, Ruth Becky, Speech and Hearing Therapy. Pittsburgh: Stanwix House, Inc. (1969).

LaPointe, Leonard I. and Williams, William N., "Effect of Selected Form Attachment Devices on Oral Stereognosis Scores." Perceptual and Motor Skills, 32, 469-470 (1971).

MoCall, Gerald N., "The Assessment of Lingual Tactile Sensation and Perception." J. Speech and Hearing Dis., 34, 151-156 (1969).

McCroskey, R. I., Jr., "The Relative Contribution of Auditory and Tactile Cues to Certain Aspects of Speech." Southern Speech J., 24, 834-90 (1958).

McDonald, Eugene $T$. and Aungst, Lester F., "Studies in Oral Sensory Function," in Bosma, J. F. (ed.), Symposium on Oral Sensation and Perception. Springfield, Ill.: Charles C. Thomas (1967). pp. 202-220.

Moser, Henry M. and Houck, Rose E., "A Study of the Lingual Orientation of Normal and Articulatory Defective Speakers on a Test of Lingual Identification of Selected Arrangements of Haptic Forms," in Bosma, J. F. (ed.), Second Symposium on Oral Sensation and Perception. Springfield, Ill.: Charles C. Thomas (1970). pp. 398-409.

Mysak, E., "A Servo Model for Speech Therapy." J. Speech and Hearing Dis., 24, 144-149 (1959).

Pleasonton, Anna K., "Sensitivity of the Tongue to Electrical Stimulation." J. Speech and Hearing Res., 635644 (1970).

Ringel, Robert L., "Oral Region Two-Point Discrimination in Normal and Myopathic Subjects," in Bosma, J. F. (ed.), Second Symposium on Oral Sensation and Perception. Springfield, Ill.: Charles C. Thomas (1970). pp. 309-322.

and Ewanowski, Stanley J., "Oral Perception: 1. Two-Point Discrimination." J. Speech and Hearing Res., 8, 389-398 (1965). 
Ringel, Robert L, and Steer, M. D., "Some Effects of Tactile and Auditory Alterations on Speech Output." J. Speech and Hearing Res., 6, 369-378 (1963).

Ruch, T. C. and Patton, H. D. (eds.), Physiology and Biophysics. 19th ed. Philadelphia: Saunders (1965).

Rutherford, David and McCall, Gerald, "Testing Oral Sensation and Perception in Persons with Dysarthria," in Bosma, J. F. (ed.), Symposium on Oral Sensation and Perception. Springfield, Ill.: Charles C. Thomas (1967). pp. 188-201.

Schliesser, Herbert $F$, and Coleman, Ralph $0 .$, "Effectiveness of Certain Procedures for Alteration of Auditory and Oral Tactile Sensation for Speech." Perceotual and Motor Skilis, 26, 275-281 (1968).

Shelton, R., Arndt, $W_{.}$, and Hetherington, J., "Testing Oral Stereognosis," in Bosma, J. F. (ed.), Symposium on Oral Sensation and Perception. Springfield, III.: Charles C. Thomas (1967). pp. 24-35.

Skalbeck, Gretchen and Weiss, Curtis E., "Tongue Sensitivity Among Deaf Children." Submitted for publication (1974).

Torrans, Anne, "A Comparison of Methodologies for Testing Orai Stereognosis." A paper presented at the 1973 ASHA Convention.

VanRiper, Charles, Speech Correction: Principles and Methods. Inglewood Cliffs, N. J.: Prentice-Hall, Inc. (1963). pp. 14-36.

Weinberg, Bernd, Iiss, Gail, and Hillis, James, "A Comparative Study of Visual, Manual, and Oral Form Identification in Speech Impaired and Normal Speaking Children," in Bosma, J. F. (ed.), Second Symposium on Oral Sensation and Perception. Springfield, Ill.: Charles c. Thomas (1970). pp. 350-356.

Weiss, Curtis E., "The Effects of Dismupted Linguapalatal Taction on Articulation." J. Communication Dis., 2, 14-19 (1969).

"Disrupted Iinguapalatal Taction and Speech of Young Children." Perceptual and Motor Skills, 30, 714 (1970).

$$
\text { "Goings-on Inside the Mouth." Hearing and }
$$

Speech News, 41, 10-11 (1973a). 
Weiss, Curtis E., "Lingual Preference Among Children." Folia Phonia., 25, 136-139 (1973b).

Williams, William $\mathrm{N}$. and LaPointe, Leonard I., "Intramoral Recognition of Geometric Forms by Normal Subjects." Perceptual and Motor Skilis, 32, 419-426: (1971).

Woodford, I. D., Oral Stereognosis. Unpublished masters thesis, University of Illinois (1964). 


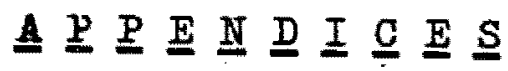




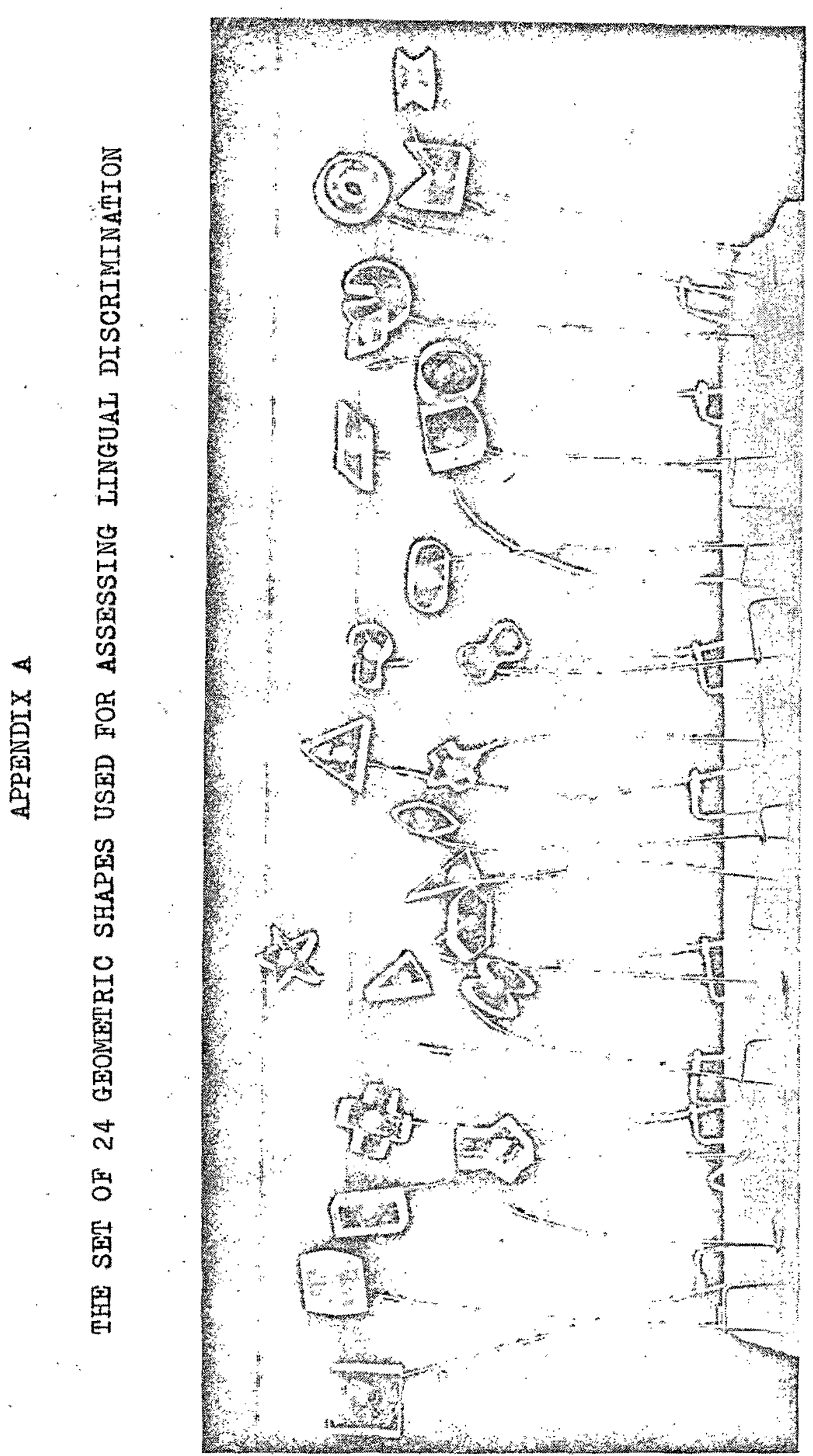




\section{APPENDIX B}

\section{IIUUSTRATION OF 24 SHAPES USED FOR ASSESSING IINGUAL DISCRININATION}

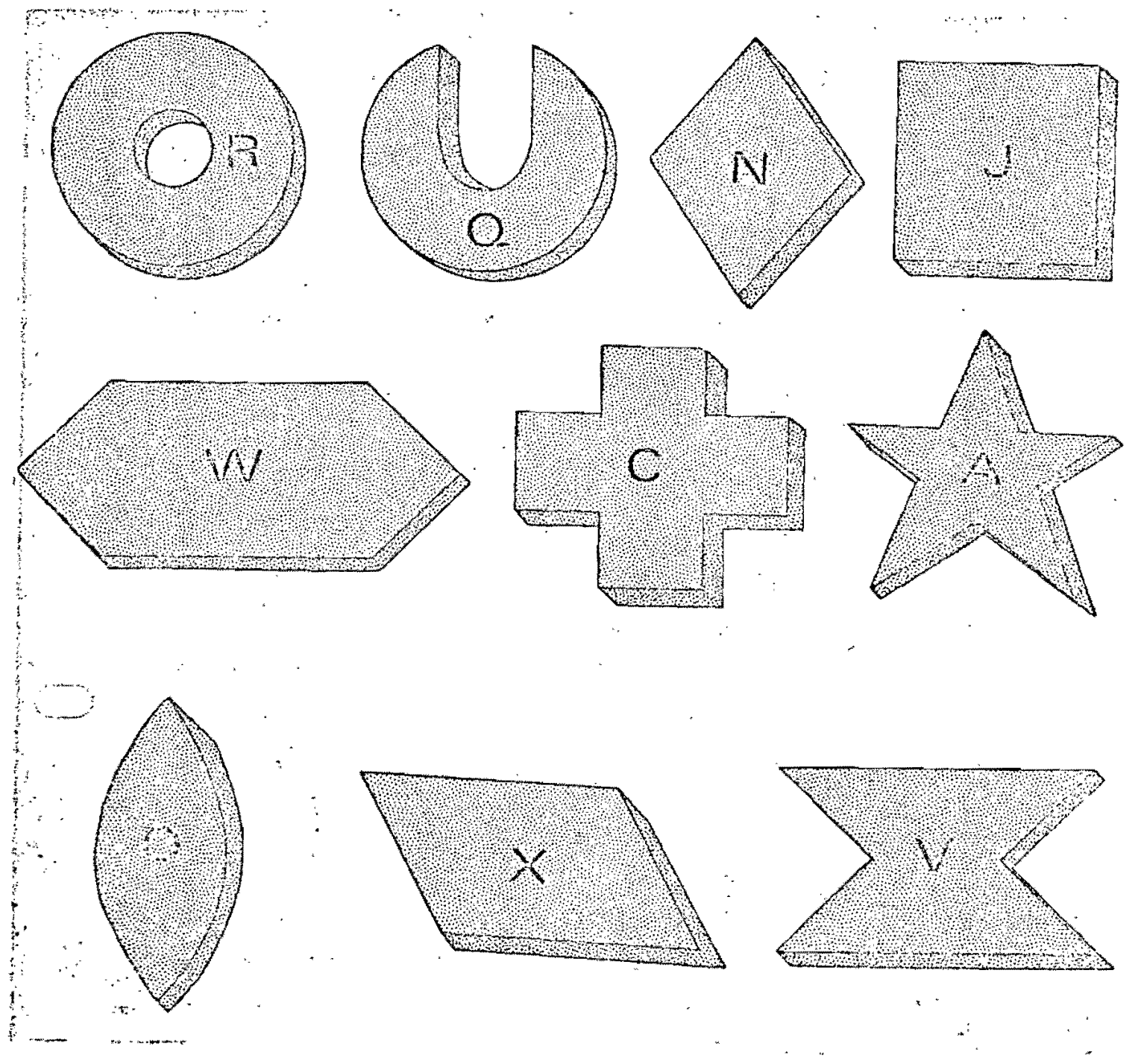



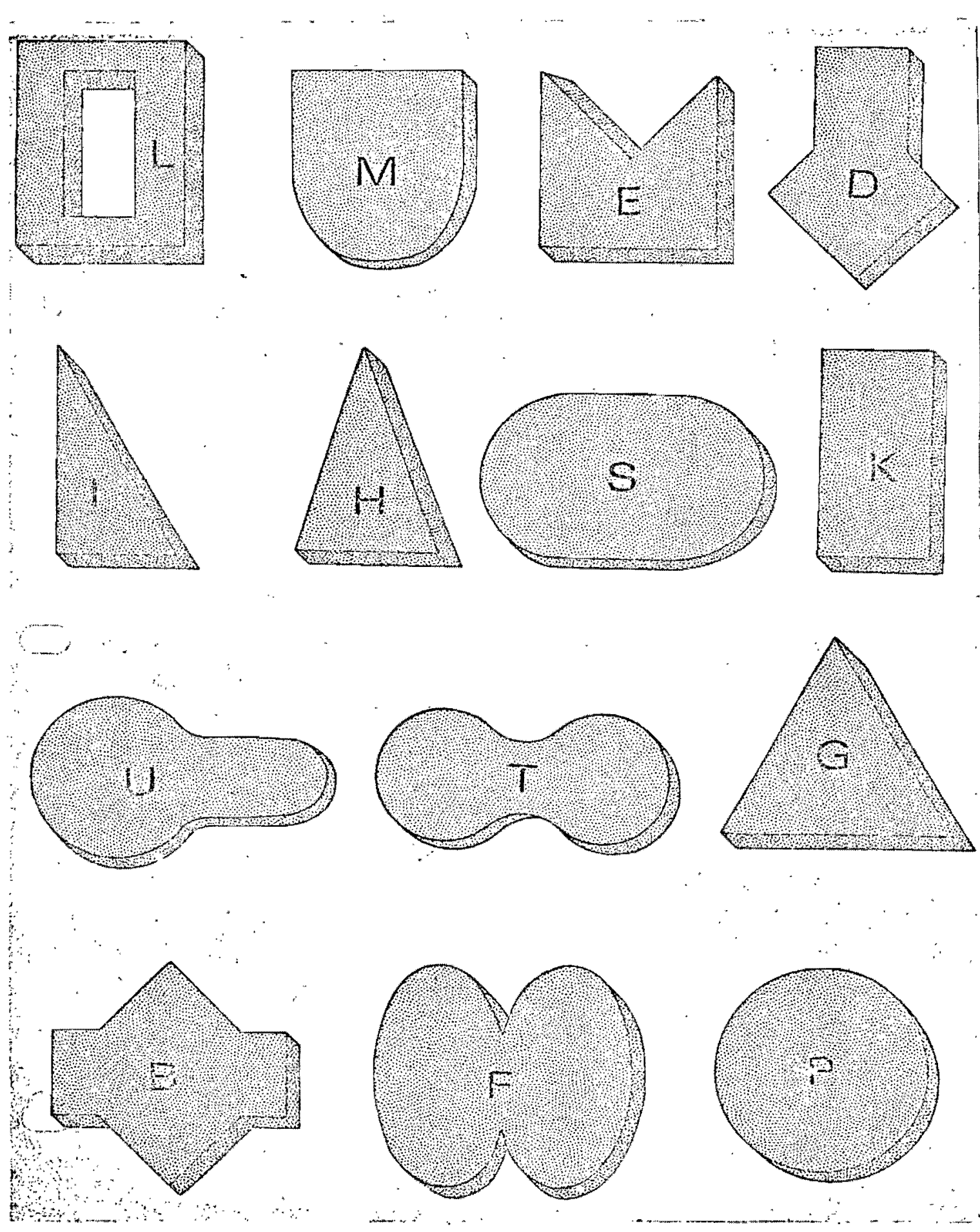
0 罢
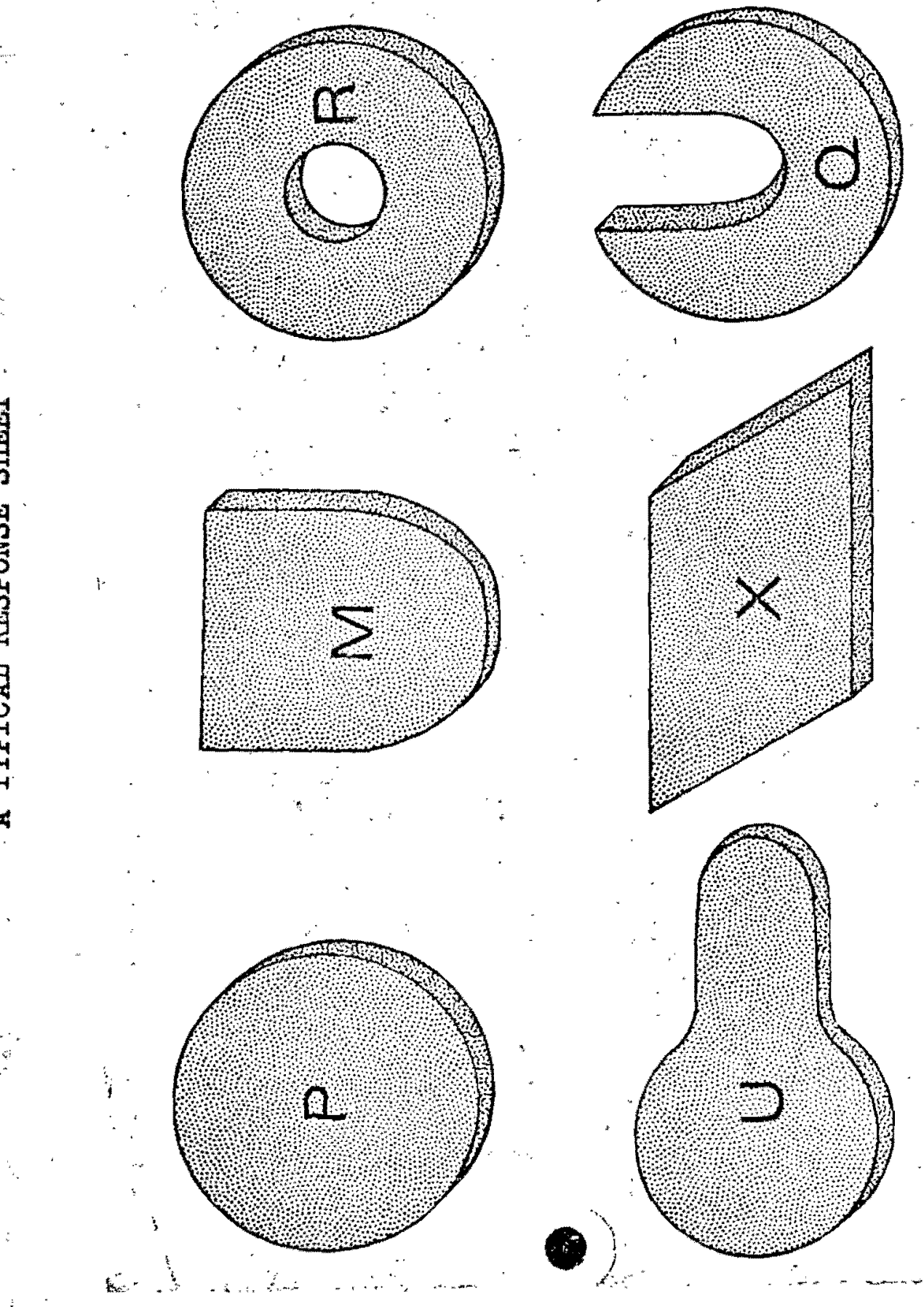


\section{APPENDIX D}

AN EXAMPIE OF THE SCORE SHEET USED FOR ALI SUBJECTS

Subject

Age

Grade occupation
Date

Comments

Time

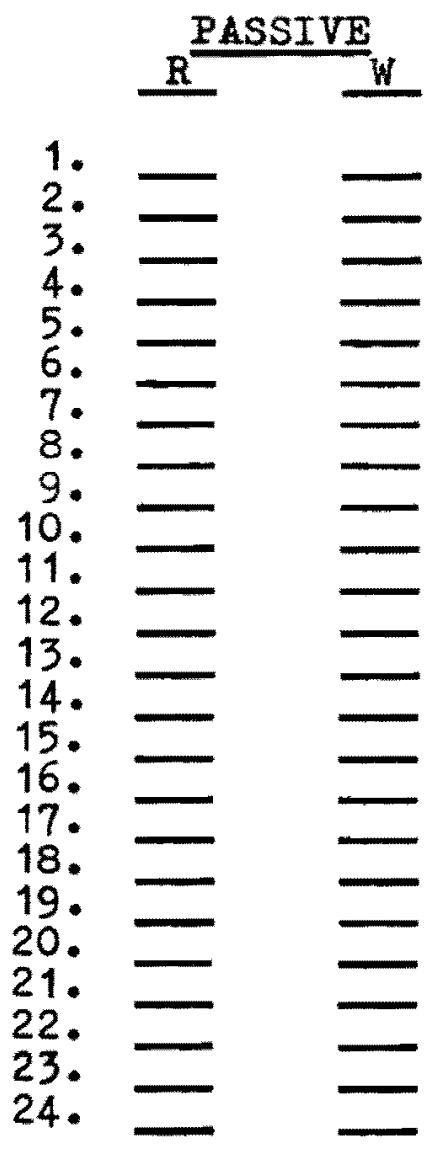

TOTALS

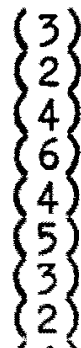

(1)

$\left(\begin{array}{l}1 \\ 6 \\ 6\end{array}\right.$

$\left\{\begin{array}{l}6 \\ 5 \\ 2 \\ 4\end{array}\right\}$

$\left\{\begin{array}{l}2 \\ 4 \\ 5\end{array}\right\}$

$\left\{\begin{array}{l}5 \\ 1 \\ 3\end{array}\right\}$

$\left\{\begin{array}{l}3 \\ 3 \\ 6\end{array}\right\}$

$\left(\begin{array}{l}6 \\ 3\end{array}\right.$

$\left\{\begin{array}{l}1 \\ 4\end{array}\right.$

$\left(\begin{array}{l}4 \\ 1 \\ 6\end{array}\right)$

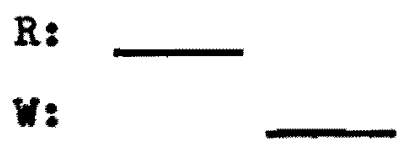

PERCENTAGE CORRECT

ACPIVE

$R \quad W$

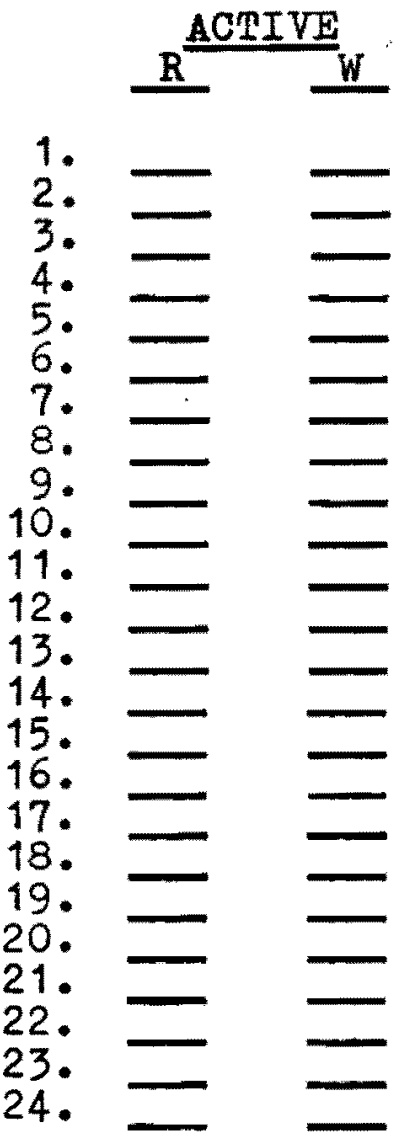

TOTAIS

R:

W:

PERCENTAGE CORRECT 


\section{APPENDIX E \\ INSTRUCTIONS TO SUBJECTS}

\section{Orientation}

The investigator presented the two pictures with all shapes illustrated and said, "I want you to look at these shapes." A plastic triangular shape was presented with the statement, "Point to the picture that looks like this."

\section{Instructions for Passive Administration}

"I am going to ask you to close your eyes and open your mouth and then I will put a plastic shape in your mouth for five seconds while you keep your mouth open. Do not move your tongue. After I remove the shape, open your eyes and point to the picture of the shape you think you had in your mouth."

Instructions for Active Administration

"After you have closed your eyes, I am going to place a shape behind your upper front teeth. I want you to explore the entire shape with your tongue while your mouth is open. After I remove the shape, open your eyes and point to the picture of the shape you think you had in your mouth." 